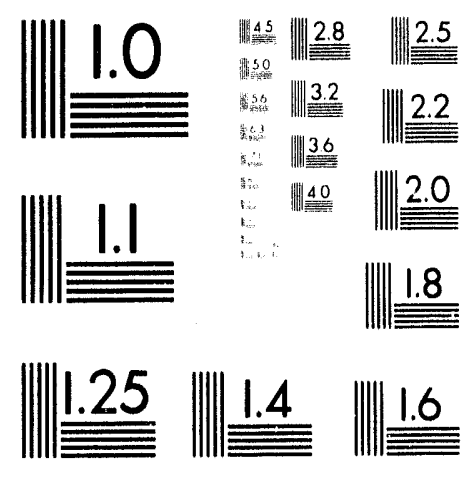



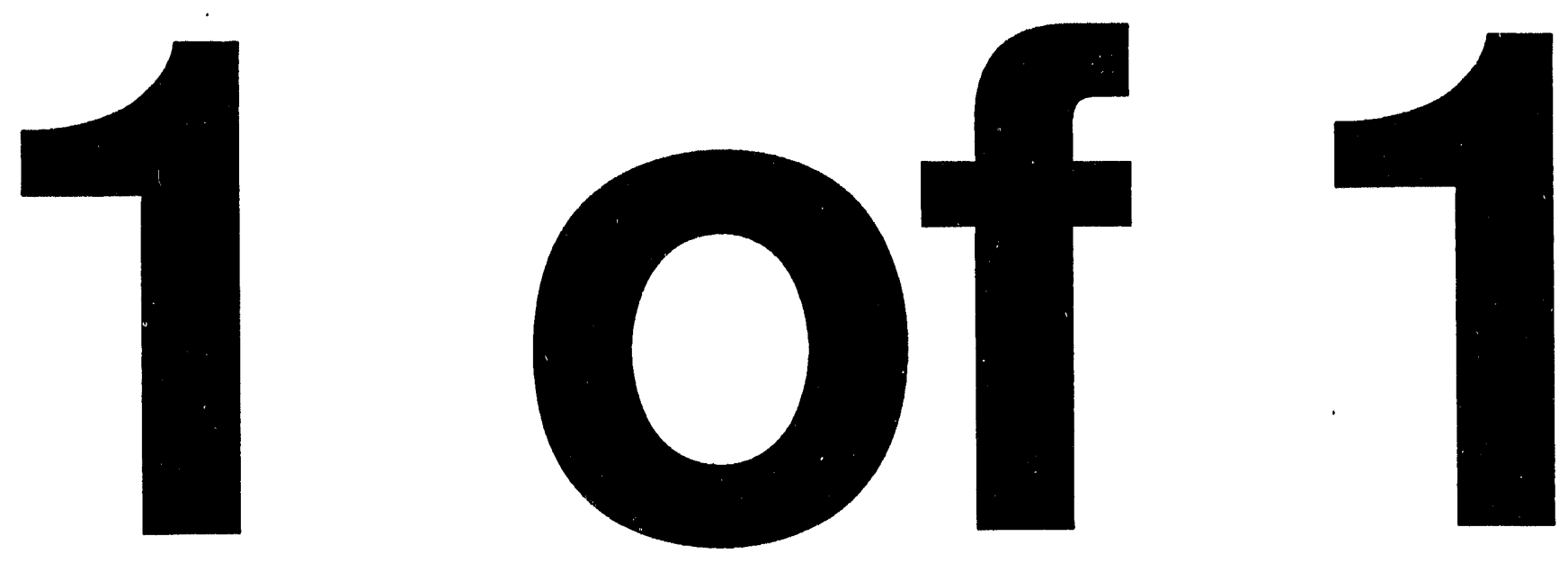


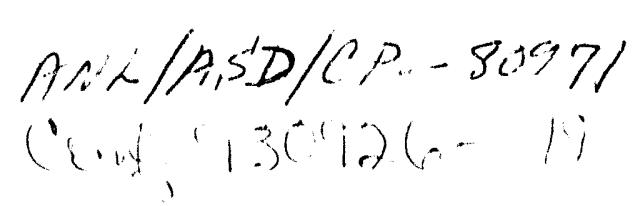

\title{
Superconducting Magnet Design for Fixed-Field Alternating-Gradient (FFAG) Accelerator
}

\author{
Mostafa Abdelsalam \\ Universily of Wisconsin - Madison, Madison, Wisconsin 53706 \\ Robert Kustom
}

Advanced Photon Source, Argonne National Laboralory, Argonne, Illinois 6(1)4.39

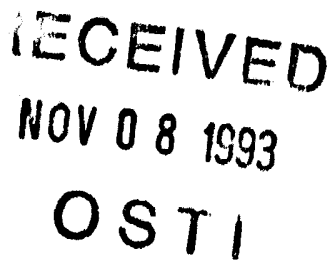

\begin{abstract}
The FFAG accelerator requires static fields that increase with radius along the accelerator midplane according to $B=B_{n}\left(R / R_{n}\right)^{13.4}$. The field is generated by equally spaced magnets around the circumference and varies from a maximum of $4.1 \mathrm{~T}$ to a minimum of $-1.9 \mathrm{~T}$. The general coll design employs cryostable magnets wound with aluminum stabilized superconductor. Each magnet has resistive pole face windings outside of the cryostat to bllow for field fine tuning after construction. A set of iron-free coil windings generate the refuired fleld distribution.
\end{abstract}

\section{INTRODUCTION}

Proposals have been made 10 build a rixed-Field Altermating-Gradient (FFAC) $|1|$ accelentor as a source of pulsed protons for a spallation neutron target $[2|| 3 \mid$, . These accelerators are non-isochronous and accelerate using frequency modulated cavities. The magnets are DC-excited with a field strength that varies with radius as $B_{01}\left(R / R_{11}\right)^{k}$, where $B_{0}$ is the injection field, $R_{0}$ is the average injection radius (circumferential path length $2 \pi$ ), and $k$ is a constant called the field index.

A typical layout of an FFAG accelerator is shown in Fig. 1 , where the black rectangles on the circumference are sector magnets which provide a magnetic field variation along the circumferential particle orbit shown in Fig. 2. The negative fields deflect positive charged protons radially outwards and the positive fields deflect the particles radially inwards. The peak positive field is considerably stronger to provide a net bending radius which defines the average radius, $R$.

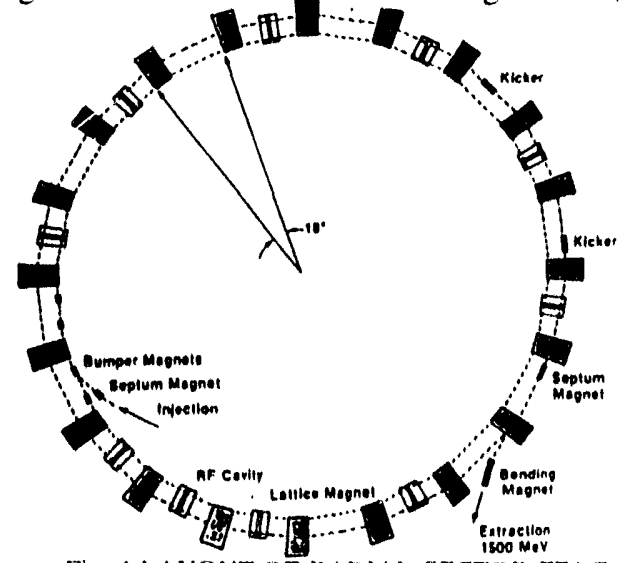

Fig. I.LAYOUT OF RADIAL-SECTOR FFAG.

Manuscript submitted September 21, 1993

Work supported by US. Department of energy, Office of Basic Sciences, under contract $W-31-109-E N G-38$.

The submitted manuscript has been authored by a contractor of the U.S. Government undet contract No. W.31-109-ENG-38. Accordingly, the U.S. Government retains a Accordigiv, the U. S. Gaverense to publish nonexclusive, royaly-frea lised form of this or reproduce the published form of this U. S. Government purposes.

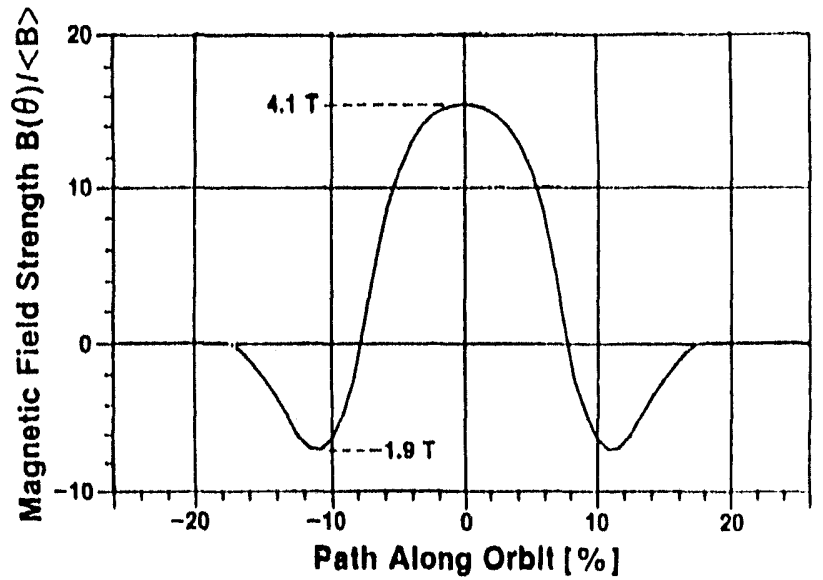

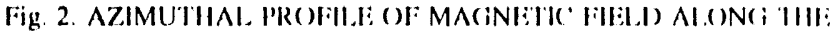
PATH OF ONE CELL, AT EXTRACIION ENERGYY.

Beam is injected at the inside radius of the FIAC at low energy and is accelerated to higher energy if cavities located between sector magnets. As the beam gains energy, the average radius increases until the extraction energy is reached at the outer ranus. The parameters for a $15(5)()-\mathrm{MeV}$ III $\wedge(i$ including sector magnet fields are listed in Table 1.

TAIBILI I

PARAMETERS FOR THIE FFAC ACCILLERATOR

Extraction Energy, MeV

1500

Extraction Radius, $\int \mathrm{d} s / 2 \pi, \mathrm{m}$

Injection Energy, $\mathrm{MeV}$

$28.14 \mathrm{~m}$

Injection Radius, $\int \mathrm{d} s / 2 \pi, \mathrm{m}$ 350

Field Index, $\mathrm{k}$

26.37

Peak Positive Bending Field @ Extraction, T

13.4

Peak Negative Bending Field @ Extraction, T

4.1

Peak Positive Bending Field @ Injection, T

Peak Negative Bending Field@ Injection, T

0.796

Horizontal Tune

4.25

Vertical Tune

3.25

Horizontal Emittance, mmmr $\quad 650 \pi$

Vertical Emittance, mmmr $\quad 500 \pi$

Repetition Rate, $\mathrm{Hz} \quad 250$

Maximum RF Voltage, $\mathrm{kV}$

Maximum RF Frequency (Extraction), $\mathrm{MHz}$

400

1.565

Maximum RF Frequency (Injection), $\mathrm{MiHz}$

1.241

The use of superconducting magnets is a natural choice lor generating this do field because of the $4.1 \mathrm{~T}$ requirement. Because a large beam current with a high repetition rate is required to be accelerated by the $F F \wedge G$, the use of low 7 .

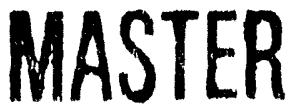


material, like aluminum, is desired to minimize induced radioactivity due to beam loss. The magnets, therefore, will be designed with high purity aluminum as stabilizer and high strength aluminum for structural purposes. The vactum chamber will also be aluminum.

Normal conducting aluminum pole fice windings will be placed between the vacuum jacket of the superconducting magnets and the vacuum chamber for the proton beam. These coils will be used for final adjustment of the magnetic field. The field excitation will be provided without the use of iron, although some iron might be provided for fringe lield reduction.

\section{Magnet Configututation}

The problem of magnet configuration design is solved in two steps; the first is choosing an arrangement of coils that, with the "proper" current in each one, will achieve the required, or larger, field distribution. The secome step is to find these "proper" currents. This step is reduced (o solving the reverse problem of finding the currents in a set of coils that generate a specified field distribution.

Through a combination of intuition and trial and error, several configurations are allempted. Fig. 3 shows two symmetrical sets, above and below the orbital plane, of a 6-coil core configuration that provides the correct field pattern. Fig. 4 shows the target field over the radius at the plane of symmetry along with that achieved with the 6-coil configuration. Fig. 5 shows the target and achieved azimuthal fields at the extraction radius for the same coil configuration. The coil sizes and required excitation currents are listed in Table 2. A plan view wire schematic of the 6-coil configuration showing current directions and identifying different coil segments is shown in Fig. 6.
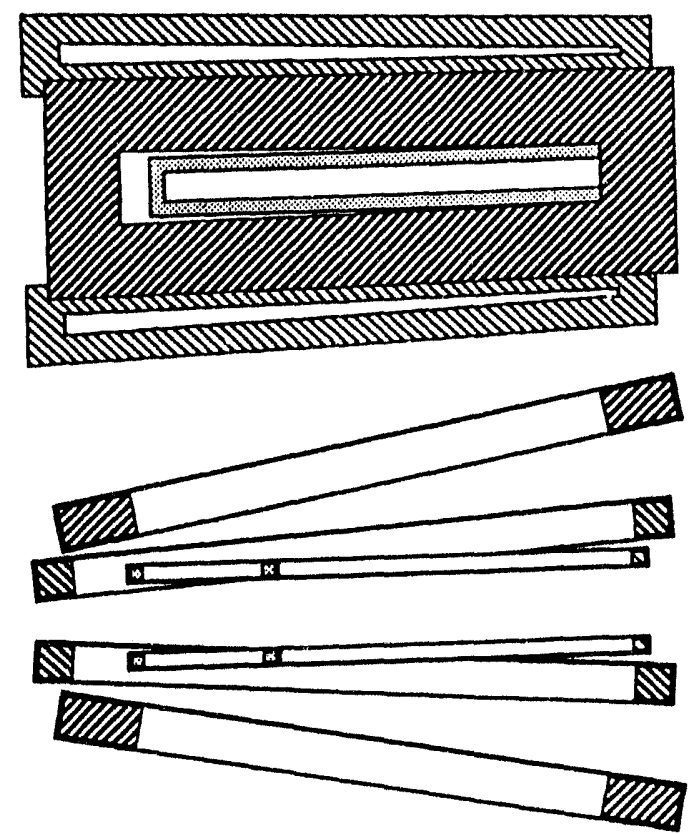

Fig. 3. 6-COIL. ARRANGEMENT

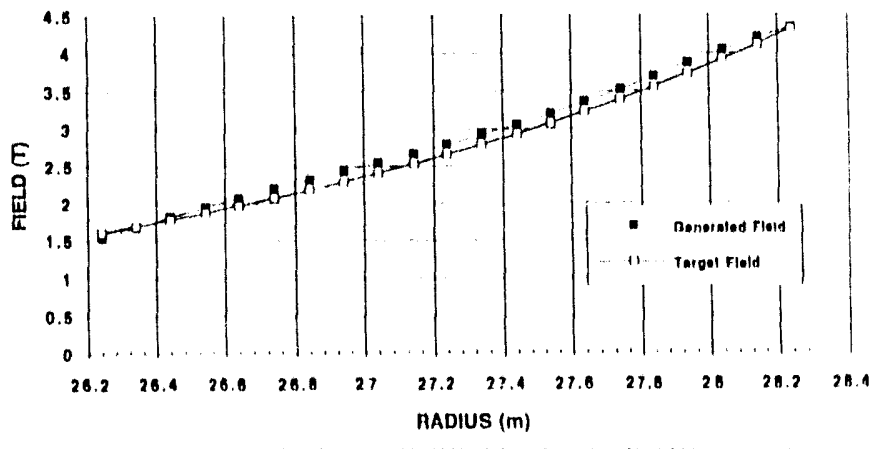

Fig 4 FIILI) AI II.ANE (OF SYMMETKY FOR THE G.(')II DESIGN.

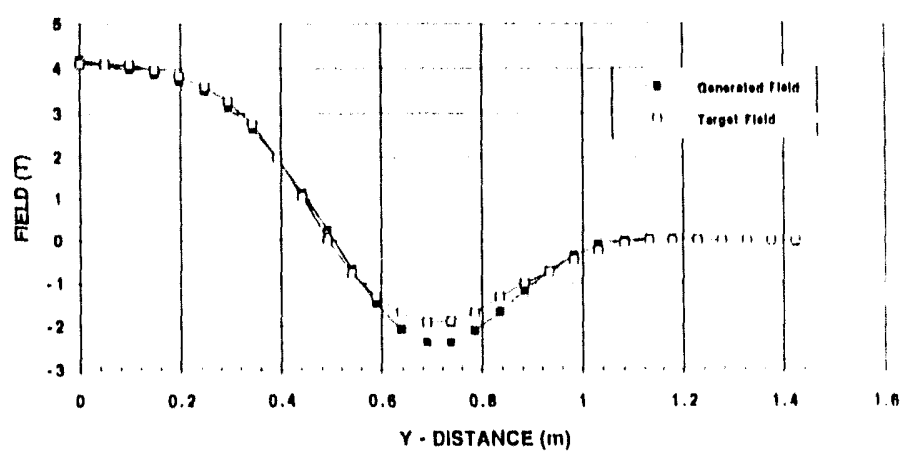

Fig. 5. FIELI) AT (OUTER RAI)IUS FOK THE G-(OII, I)ESI(IN

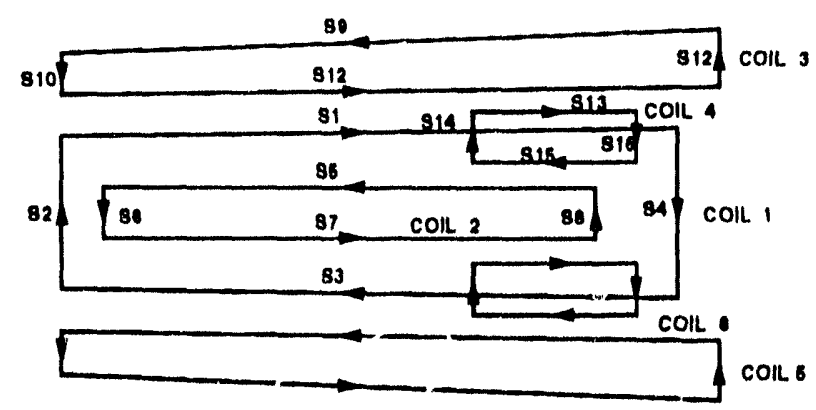

Fig. 6 WIRE SCHLMATIC OF THE 6-C(OII. ARRANGEMIINT.

Normal conducting pole face windings would be placed between the beam vacuum chamber and outer cryostat wall of the sector magnets to fine tune the magnetic field and the beam.

The coordinates of the four corner points of the center line of each coil are listed in Table $2 a$. The $x$-coordinate is the radial direction in the Fi: $A C$ and the $z$-coordinate is measured in meters perpendicular to the orbital plane. The $y$-condinate is the distance along the beam orbit measured from the vertical plane of symmetry. Currents, in ampere-lurns, along with current density, in amperes per square meter, and total ampere-meters of these corils are listed in Table $2 \mathrm{~b}$. 
TABLL: 2

COIL, PARAMIETERS.

П. C(OIL. COORIDINATES ANI) DIMENSIONS IN METERS

\begin{tabular}{lccccccc}
\multicolumn{1}{l}{ coil \# } & $X$ & $Y$ & $Z$ & $X$ & $Y$ & $Z$ & $W / 11$ \\
1 & 28.8 & .402 & 0.50 & 25.8 & .360 & 1.10 & 0.40 \\
& 25.8 & -.360 & 1.10 & 28.8 & -.402 & 0.50 & 0.25 \\
2 & 28.4 & .124 & 0.25 & 26.0 & .113 & 0.25 & 0.06 \\
& 26.0 & -.113 & 0.25 & 28.4 & -.124 & 0.25 & 0.10 \\
3 & 29.0 & .860 & 0.25 & 25.3 & .766 & 0.45 & 0.20 \\
& 25.8 & .540 & 0.45 & 29.0 & .607 & 0.25 & 0.15 \\
4 & 28.6 & .420 & 0.25 & 27.8 & .420 & 0.25 & 0.08 \\
& 27.8 & .243 & 0.25 & 28.6 & .250 & 0.25 & 0.10 \\
5 & 29.0 & -.860 & 0.25 & 25.8 & -.766 & 0.45 & 0.20 \\
& 25.8 & .540 & 0.45 & 29.0 & .607 & 0.25 & 0.15 \\
6 & 28.6 & .420 & 0.25 & 27.8 & .420 & 0.25 & 0.08 \\
& 27.8 & .243 & 0.25 & 28.6 & .250 & 0.25 & 0.10
\end{tabular}

b. COILS GROSS (UIRRIENTS, CURRENT I)ENSTTHES ANI) THEIR TOTAL. AMPIERT: MIITIRS

$\begin{array}{llcc}\text { coil \# } & \begin{array}{l}\text { Current } \\ \text { (A turus) }\end{array} & \begin{array}{c}\mathrm{J} \\ \text { (kA/cm2) }\end{array} & \begin{array}{c}\text { IS } \\ (\text { (Am) }\end{array} \\ 1 & -6.734 \mathrm{E}+06 & 6.73 & 5.1471 \mathrm{i}+07 \\ 2 & 3.135 \mathrm{E}+05 & 5.22 & 1.653 \mathrm{E}+06 \\ 3 & 2.357 \mathrm{E}+06 & 7.86 & 1.662 \mathrm{E}+07 \\ 4 & -5.234 \mathrm{E}+05 & 6.54 & 1.106 \mathrm{E}+06 \\ 5 & 2.357 \mathrm{E}+06 & 7.86 & 1.662 \mathrm{E}+07 \\ 6 & -5.234 \mathrm{E}+05 & 6.54 & 1.106 \mathrm{E}+06\end{array}$

Positive current is counterclockwise.

\section{MAGNET DESIGiN}

It is highly desirable to make the FFAG magnets cryogenically stable to avorid operation disruption and beam loss that would result from magnet quenches. The probability of these quenches in unstable magnets is higher in the FFAG accelerator because the energy deposited on a conductor section from an occasional stray beam might be large enough to induce a transition from the superconducting state to the normal one.

The FFAG coils will be wound with monolithic high purity aluminum (HPAL) stabilized conductor with NbTi strands as shown in Fig. 7. HPAL has the advantage of low resistivity at liquid helium temperature and tolerable magnetoresistivity in magnetic fields. The conductor will be cooled in a bath of liquid helium. The choice between normal and superfluid helium cooling will depend on the results of the stability analysis. The conductor will be embedded in a high strength aluminum (HSAL) support as shown in Fig. 8 .

The windings will experience large magnetic forces resulting from their own fields and the interaction with other magnets. These magnetic forces have been calculated using the computer program EFFI [4|. Magnet supports will be designed to be strong enough to react to these forces and rigid enough to maintain the windings in their positions within an acceptable tolerance. The force between segments
SI and S3 is 5.2.2. MN and is repulsive. The support structure will be inside the helium chamber to minimize refrigeration load. The proposed frame for the suppont structure will be mate of thick HSAI, plates. Jach of the top and bottom segments of SI and S.3 have alltative forces of $8.14 \mathrm{MN}$. $\wedge$ box frame will be designed to hold ihe coils apart. Special frames will be designed for the injection and extraction beiln lociltions.

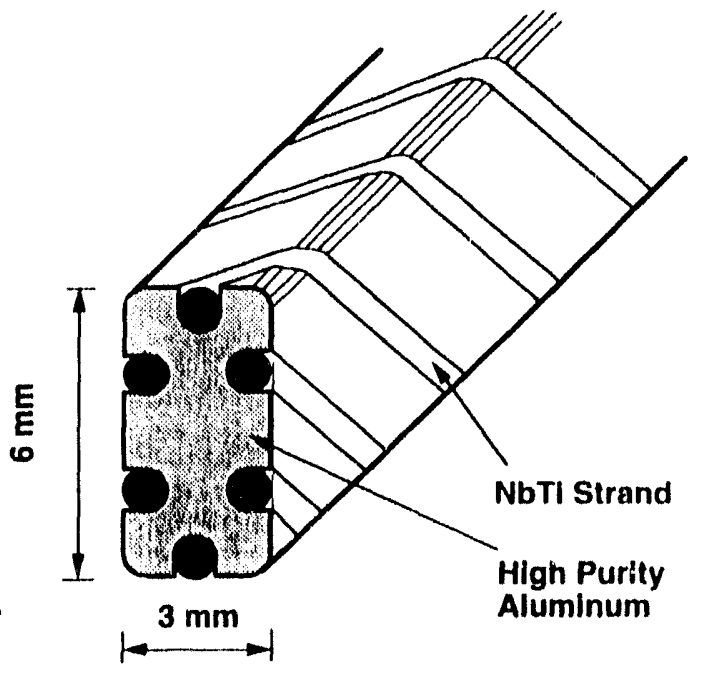

Fig 7. $5 \mathrm{KA}$ IIPAL, SIABIL.IZEI) (ONI)UCTOR

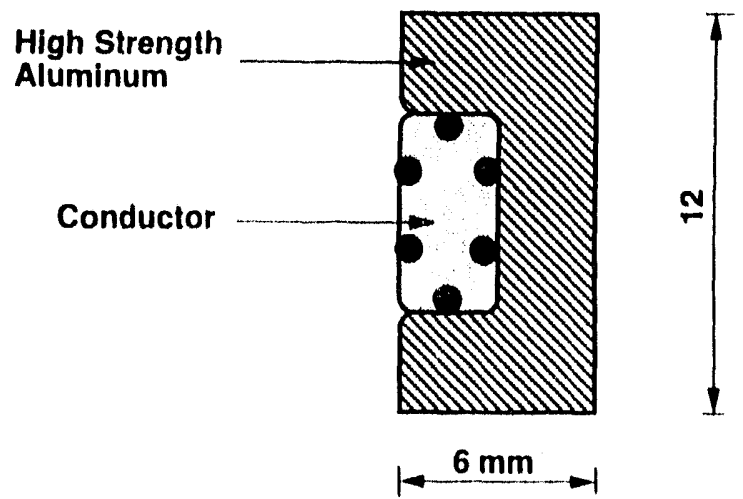

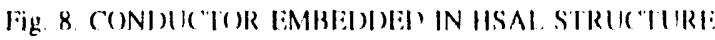

\section{REFIERENC'LS}

II F. T. Cole. el al., "Electron model fixed fiede allermating gradient accelerator," Review of Scientific Instruments, Vol 28. No. 6, Jume, 19.57

12) T. K. Khoe and R. L. Kustom, "ASPUN, design for an Argonne super intense pulsed neutron soures," IlESE Trans. an Nuclear Science. NS-30), No, 4, 1983

1.3] P. F. Mends, dr. and G. Wustefeld, "An Fisci compressur and accelerator ring studied for llie (ierman spallation mentron sounce," |l|l:1: Trans. on Nuclear Science, N.S-32, No. 5, 198.5

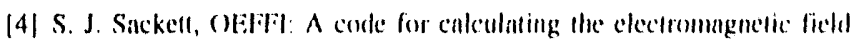
inductance in coil systems of arbitraty geonkelry, laweence l.ivermons Laboratory, Livermore, ('A. U('RL. 5241)2, March 1978 


\section{DISCLAIMER}

This report was prepared as an account of work sponsored by an agency of the United States Government. Neither the United States Government nor any agency thureof, nor any of their employees, makes any warranty, express or implied, or assumes any legal liability or responsibility for the accuracy, completeness, or usefulness of any information, apparatus, product, or process disclosed, or represents that its use would not infringe privately owned rights. Reference herein to any specific commercial product, process, or service by trade name, trademark, manufacturer, or otherwise does not necessarily constitute or imply its endorsement, recommendation, or favoring by the Unitci States Government or any agency thereof. The views and opinions of authors expressed herein do not necessarily state or reflect those of the United States Government or any agency thereof. 

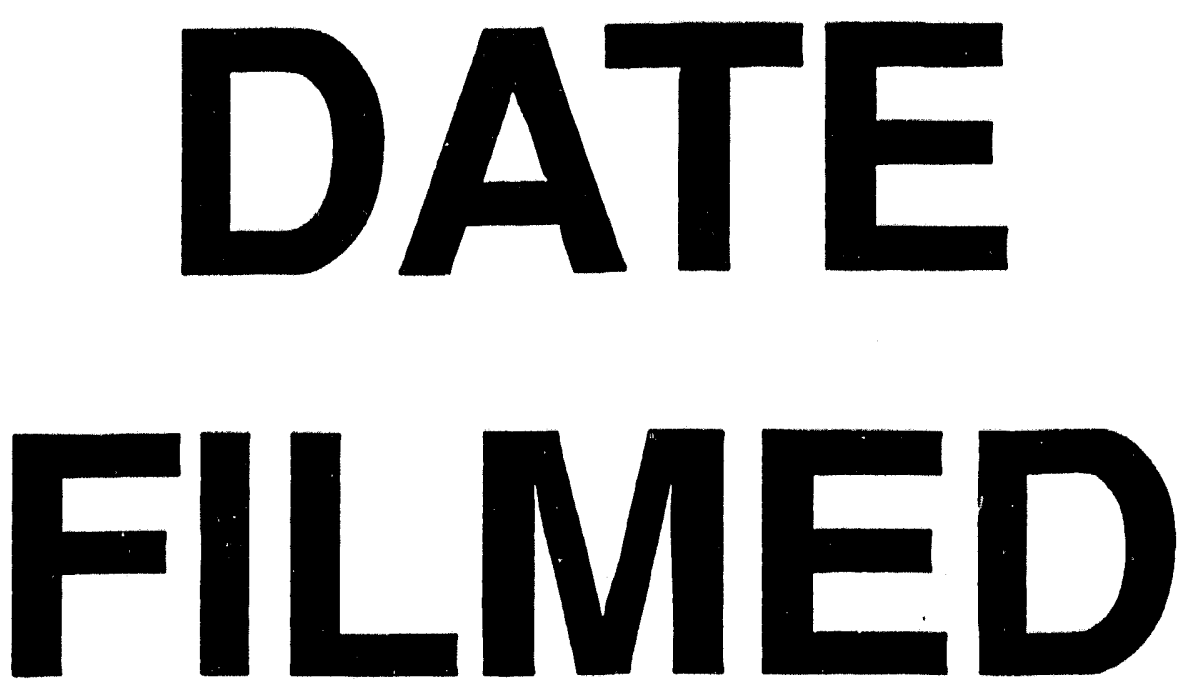

$12 / 22 / 93$
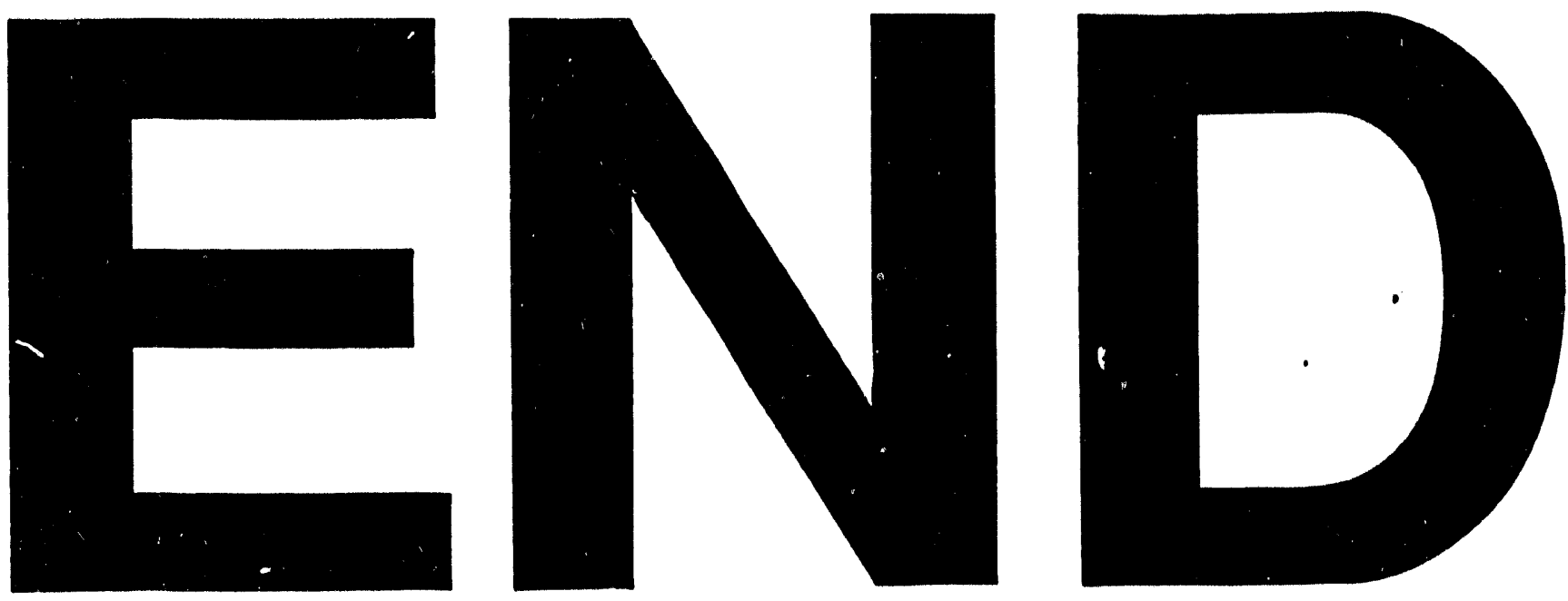
